\title{
Determining potential for on-farm fecal collection for DNA
}

\section{extraction}

C. Hall, J. K. Farney, and L. K. Mamedova

Department of Animal Sciences and Industry, Kansas State University, Manhattan

\section{Introduction}

Grazing cattle diet composition determination methods include: field observations, ruminal or esphogial contents, fecal microhistological analysis, and "Markers" (saturated hydrocarbons, alkanes) but can be labor intensive, costly, and under/over predicts some plants in the diet (summarized by Ho et al., 2010) - Wildlife researchers have used fecal samples and DNA to determine mammalian intake of feeds, but quantification of exact diet composition was not determined (Jarman et al., 2002; Deagle et al., 2005; Deagle and Tollit, 2007)

Ruminant plant fecal identification has been completed with moderate success, but diet quantification was not attempted

can be reduced by temperature and UV radiation in rabbit fecal DNA analysis has not been completed

\section{Objective}

The intention of this project is to determine DNA concentration differences based on fecal physical composition, time of collection and animal classification.

\section{Experimental Procedures}

Holsteins $(n=4)$, heifer calves $(n=3)$, and dry, pregnant beef cows $(n=4)$ were fed a diet at $1.68 \%$ of $B W$ for $21-d$

- $20 \%$ alfalfa, $50 \%$ fescue, $20 \%$ corn, and $10 \%$ soybean meal (DM basis)

On d 22-24 at 7 AM and 3 PM individual fecal samples were collected and on $\mathrm{d} 25$ at $7 \mathrm{AM}$

- FRESH: sample collected directly from cow or from ground when observing defecation

- DRY: dry sample collected from pen. Samples were $\sim 90 \%$ dry in the fecal pile

- Samples frozen immediately at $-20^{\circ} \mathrm{C}$

- DNA was extracted following kit protocols (Quiagen Quick Spin Fecal DNA kit, illustrated in Figure 1)

- Purity and quantity were assessed through a spectrophotometer. Samples with a low 280/260 ratio underwent a DNA contamination clean-up (Zymo DNA PCR Clean-up \& Concentration Kit)

\section{Statistics}

The study is a completely randomized block design with repeated measures

Quality (280/260 ratio) and quantity (ug/mL) were analyzed using appropriate t-tests and generating 90 and $95 \%$ confidence intervals for:

- Freshness - FRESH vs DRY

- Time of day for collection - AM vs PM

- Animal classification - Cow, Holstein, or Heife

- Interactions

\section{Experimental Results and Methods}

Figure 1: Method for rapidly obtaining inhibitor-free DNA isolate from bovine
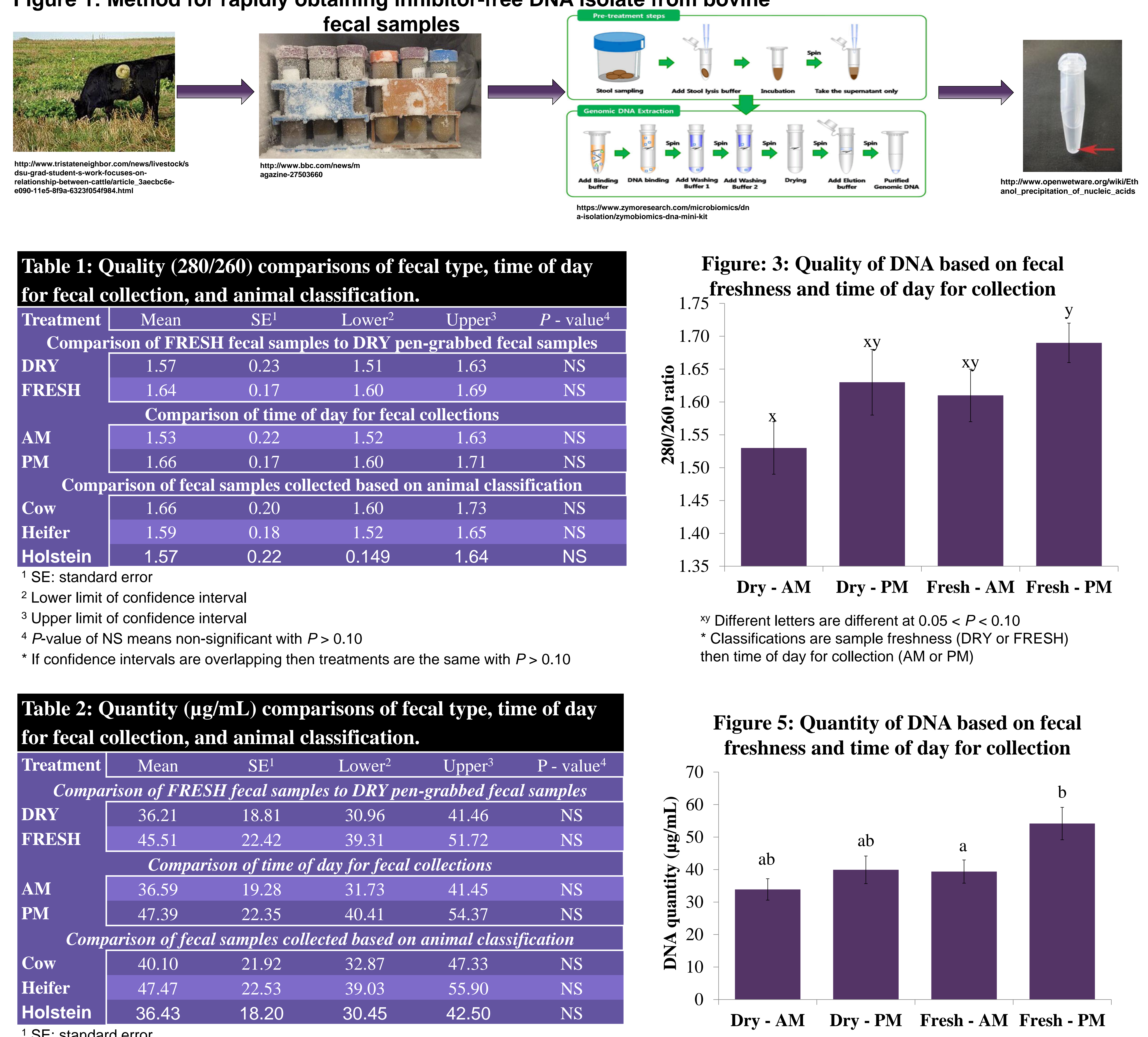

SE: standard error

Upper limit of confidence interval
$P$-value of NS means non-significant with $P>0.10$
Figure: 3: Quality of DNA based on fecal 1.70

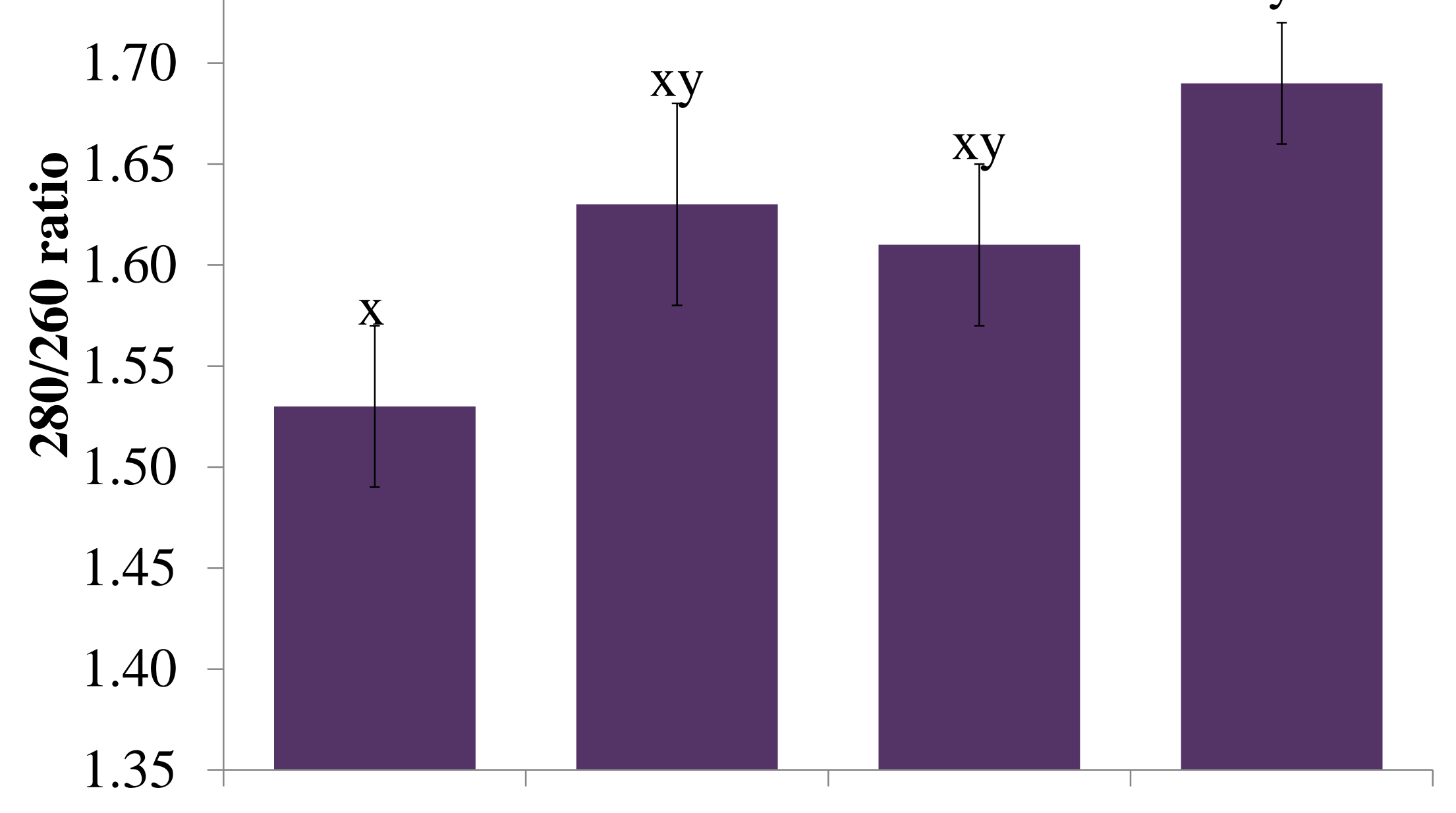

Dry - AM Dry - PM Fresh - AM Fresh - PM Different letters are different at $0.05<P<0.10$
Classifications are sample freshness (DRY or FRESH) then time of day for collection (AM or PM)

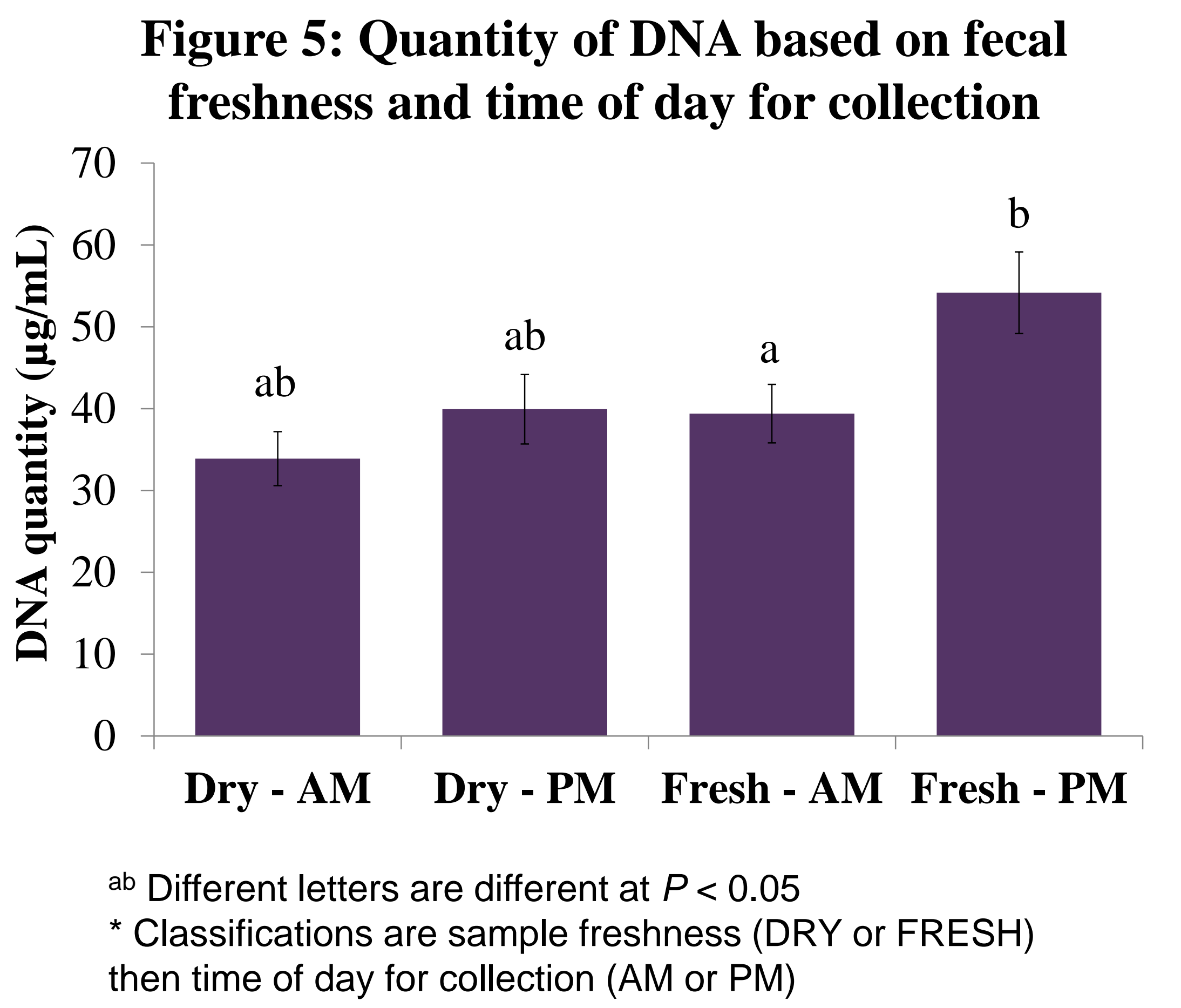
1.75 freshness and time of day for collection
Figure 2: Photos illustrating examples of fec

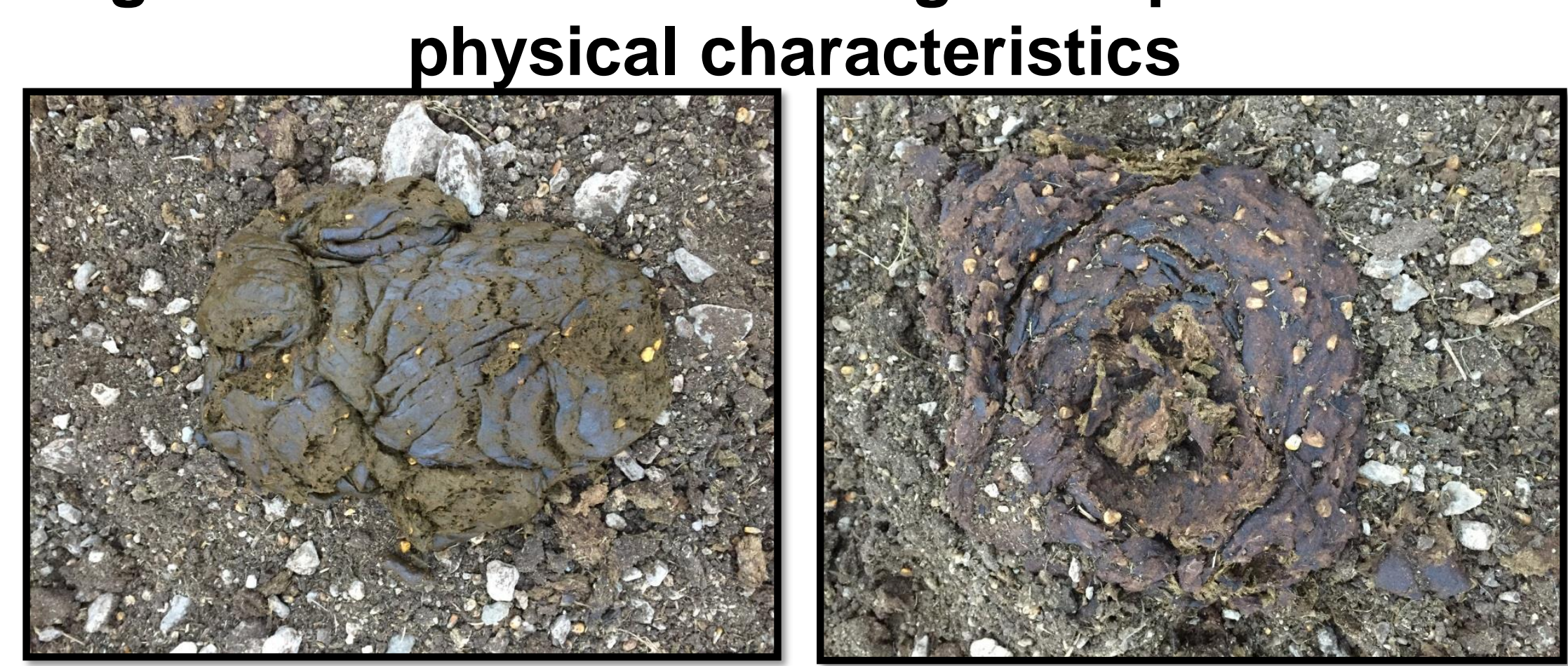

FRESH sample

DRY sample

Figure 4: Quality of DNA based on fecal

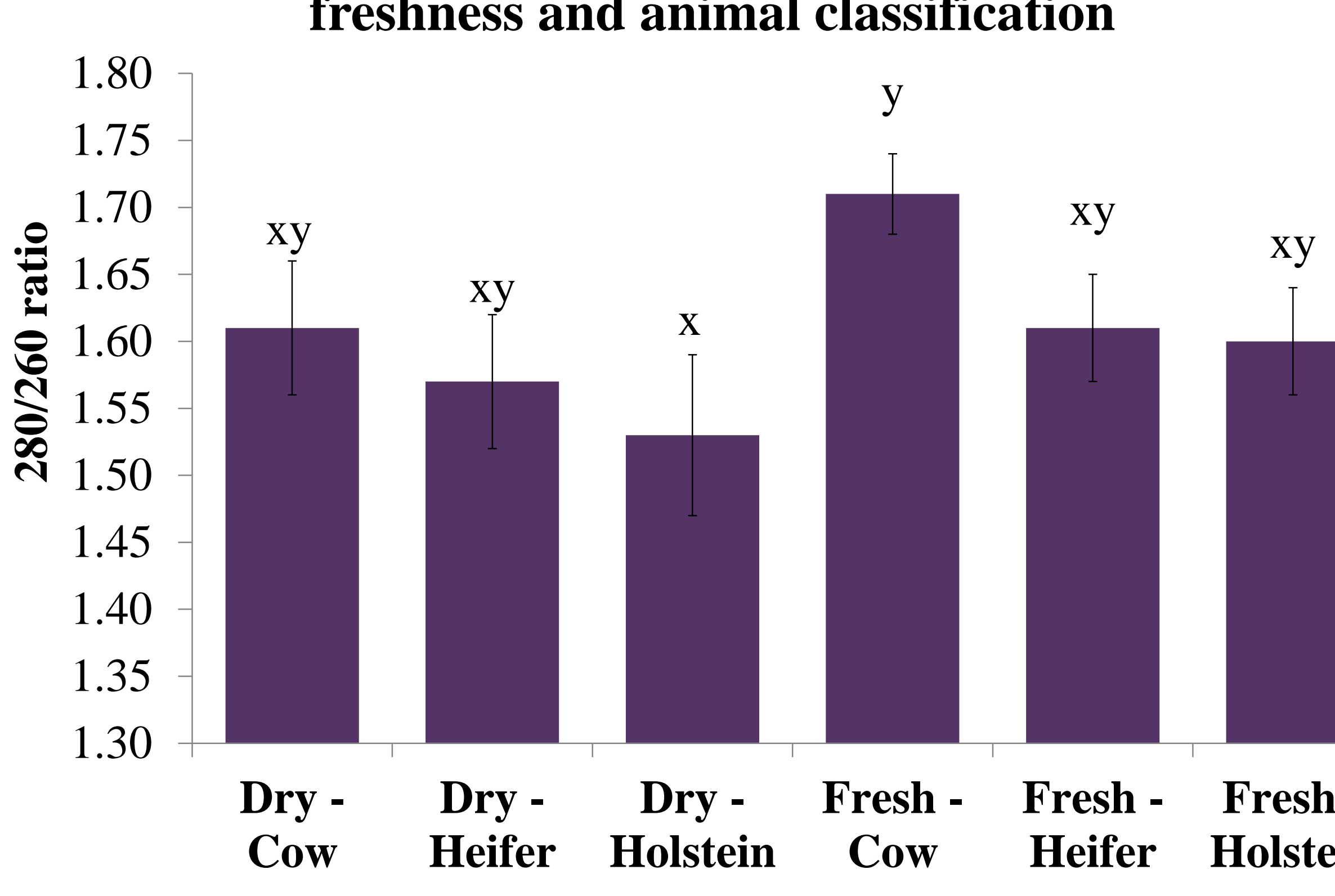

$\begin{array}{lccccc}\text { Dry - } & \text { Dry - } & \text { Dry - } & \text { Fresh - } & \text { Fresh - } & \text { Fresh - } \\ \text { Cow } & \text { Heifer } & \text { Holstein } & \text { Cow } & \text { Heifer } & \text { Holstein }\end{array}$ xy Different letters are different at $0.05<P<0.10$
"Classifications are sample freshness (DRY or FRESH) then animal
classification (Cow, Heifer, or Holstein)

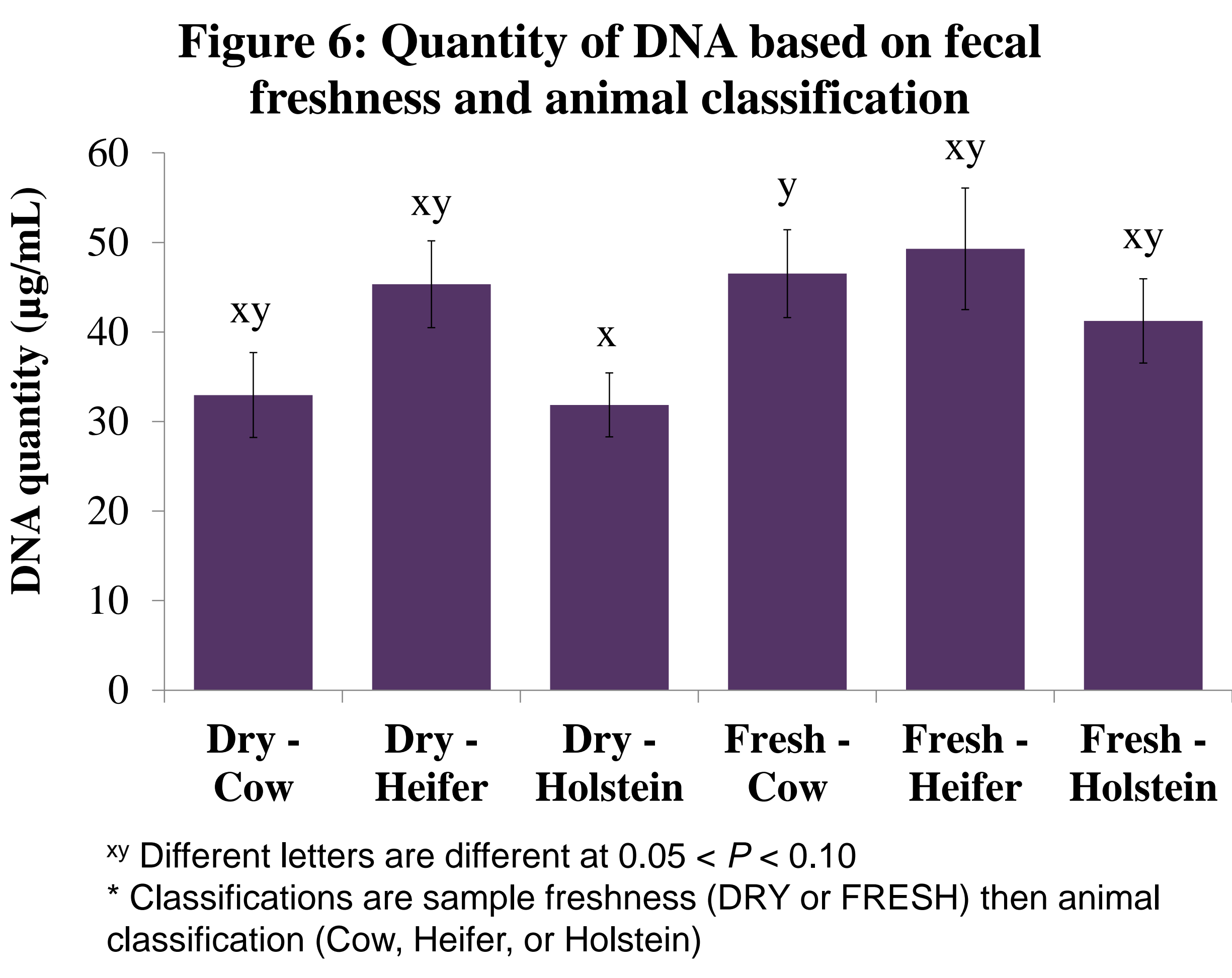

\section{Conclusions and Future Work}

Of the 105 samples analyzed, 89 had to complete a secondary clean-up to increase the 280/260 spectral reading to be $>1.4$.

There was no difference in the quantity of DNA extracted from samples that were collected FRESH or DRY; in the AM or PM; nor differences based on cattle classification.

There is evidence that a fresh sample collected in the afternoon would net the highest quality and yields of DNA to be used for downstream use in qRT-PCR.

- Possible explanation is that afternoon samples occurred $7 \mathrm{hr}$ after daily feeding which might correspond in this diet to the time of maximal ruminal digestion and undigested turnover

Overall, as with other species the fresher the sample collected the higher quality and quantity of DNA. However, for on-farm projects samples that have some moisture will still generate potentially usable DNA. 